\title{
Multidetector CT Angiography Role in Evaluation of Vascular Causes of Hemoptysis
}

\author{
OSAMA R.A. KOMBAR, M.D.*; ALI M. HASSANIN, M.D.** and AHMAD ABBAS, M.D.*** \\ The Departments of Radiology, Faculties of Medicine, Mansoura* \& Zagazig** Universities and \\ The Department of Chest, Faculty of Medicine, Zagazig University***
}

\begin{abstract}
Background: Hemoptysis has many vascular and parenchymal causes. Determining the site and the cause of the bleeding is of great value in planning the proper management.

Aim of Study: Is to evaluate the role of Multidetector Computerized Tomography (MDCT) in detection and localizing the site and causes of hemoptysis of vascular origin.

Material and Methods: Prospective study included 50 patients suffering from hemoptysis, referred to the Department of Radiology, Amiri Hospital, Kuwait during the period from April 2016 until April 2018. MDCT pulmonary and bronchial angiography was done for all patient as well as bronchoscopy, conventional angiography and biopsy were done for some cases.

Results: MDCT angiography was successful in determining the cause of hemoptysis in $88 \%$ of cases. Vsacular causes of hemoptysis included bronchial, systemic non bronchial and pulmonary arteries.

Conclusion: MDCT pulmonary and bronchial angiography is a very valuable technique in determining and the source and causes of hemoptysis and planning of management.
\end{abstract}

Key Words: MDCT angiography - Hemoptysis - Vascular causes.

\section{Introduction}

HEMOPTYSIS is defined as bleeding that originates from the lower respiratory tract, and it is can be considered as symptom of serious or even lifethreatening chest disease that require urgent investigation [1] . There are multiple causes of hemoptysis, from airway diseases, parenchymal diseases, cardiovascular diseases, and other causes [2] .

In $15-30 \%$ of all cases no definite cause can be detected, and is called idiopathic or cryptogenic hemoptysis [3]. The source of massive hemoptysis

Correspondence to: Dr. Osama R.A. Kombar, The Department of Radiology, Faculty of Medicine, Mansoura University in most of cases is the bronchial circulation. However, nonbronchial systemic arteries can be also a significant source [4]. The target of the primary diagnostic evaluation is to determine the immediate source of the bleeding and its importance, but the complete assessment requires determining the underlying primary cause of the hemoptysis. The standard diagnostic protocols have been based on combinations of conventional radiography, rigid or fiberoptic bronchoscopy, chest Computed Tomography (CT), and thoracic aortography [5] . Multidetector $\mathrm{CT}$ angiography is comprehensive, noninvasive method for detailed evaluating the whole chest including the mediastinum, lung parenchyma, and blood vessles [6]. Conditions such as bronchiectasis, chronic bronchitis, lung malignancy, tuberculosis, and chronic fungal infection are easily detected with conventional CT [7].

CT can be superior to bronchoscopy in determining the cause of hemoptysis, its main advantage being its ability to show distal airways that can't be reached by the bronchoscope, and also evaluating the surrounding lung parenchyma [3]. CT findings also can be the guide for the endoscopist about bronchial or parenchymal abnormalities and warning about possible dangers such as peribronchial or endoluminal aneurysms [8]

Known the anatomy and variant of bronchial arteries is of great value in assessment the vascular causes of hemoptysis. The bronchial arteries usually originate from the proximal descending thoracic aorta. They are termed orthotopic when they originate between the superior endplate of the T5 vertebral body and the inferior endplate of the T6 vertebral body. Bronchial arteries that originate elsewhere in the aorta or from other vasculature are termed ectopic [9] 
There are normally one or two bronchial arteries supplying each lung, arising either independently or from a common trunk [10].

On the right side, an intercostobronchial trunk usually exists, arising from the right posteromedial aspect of the aorta and coursing cranially before giving rise to one or more posterior intercostal arteries and a right bronchial arterial component. This component turns sharply in the caudal direction to the level of the right main bronchus, where it ramifies in the lung parenchyma parallel to the bronchus and more distal airways [9].

The left bronchial artery usually arises from the anterior aspect of the descending thoracic aorta, either singly ( $30.5 \%$ of cases) or as a common trunk with a second right bronchial artery $(25 \%)$. In $70 \%$ of cases, there are two left bronchial arteries in addition to the right intercostobronchial trunk. Because of its short mediastinal course, the left bronchial artery may be difficult to see clearly at single-detector row CT [9].

Ectopic bronchial artery, most commonly originating from the undersurface of the aortic arch. Potential ectopic sites of origin include the inferior aortic arch, distal descending thoracic aorta, subclavian artery, brachiocephalic trunk, thyrocervical trunk, and internal mammary artery and even a coronary artery [10]

\section{Material and Methods}

This prospective study was conducted on 50 consecutive patients with hemoptysis referred to the Department of Radiology, Amiri Hospital, Kuwait during the period from April 2016 until April 2018.

MDCT chest with angiography of the bronchial arteries was performed in multiple radiology centers, 36 men, and 14 women; 24-88 years of age; mean, 56 years of age, were referred by respiratory and cardiothoracic specialists.

Informed consent from the patients or patient's family was obtained with explanation of the study, including procedure and radiation dose.

For each patient, the following variables were recorded: Age, sex, underlying medical conditions, coagulation status, transfusion requirements, and endoscopic or scintigraphic findings, if available.

All patients were subjected to complete clinical examination with detailed history and laboratory examination with Chest X-rays.
Some cases were subjected to other investigations done after the CT study including bronchoscopy with or without histopathological examination and conventional angiographic, with correlation of the results with MDCT.

\section{Patient preparation:}

- Fasting for about 4-6h before the examination.

- An IV access was secured.

Exclusion criteria:

- Pregnant females.

- Patients with chronic renal failure or impairment not on regular dialysis.

- Severe cardiac disease causing orthopnea.

- Patients who are hemodynamically unstable.

- Sensitivity to the contrast medium.

- Patients with life-threatening hemoptysis till been stabilized.

The CT examinations were performed using 64 multidetector row CT scanner (high speed QX/i; GE Medical Systems, Milwaukee, Wis) with a gantry rotation speed of 0.5 second per rotation.

CT imaging was performed with patients in the supine position at maximal inspiration during a single breath hold.

Preliminary unenhanced CT scans with a slice thickness of $10 \mathrm{~mm}$ were obtained to detect any pre-existing hyperdense material in both lungs. Also for comparison of $\mathrm{HU}$ measurement of the suspected region of active bleeding latter on.

Then a standard technique was applied, MDCT chest with bronchial and pulmonary angiography, the scanning parameters were: Coverage area was acquired from base of neck to L2 (level of renal arteries), scanned in cranio-caudal direction, slice thickness $0.6 \mathrm{~mm}$, pitch of 1.9 , table speed of $20 \mathrm{~mm}$ per rotation, reconstruction interval of $0.6 \mathrm{~mm}$, tube voltage of $140 \mathrm{kV}$, and tube current of $586 \mathrm{~mA}$.

The following parameters $100-140 \mathrm{kV}, 90-120$ mAs, collimation $64 \times 0.6 \mathrm{~mm}$ and pitch 1.2 were used.

Optimal enhancement of both the pulmonary and systemic arteries was achieved with the injection of $120 \mathrm{ml}$ of a high-density, low osmolar nonionic contrast medium $(350 \mathrm{mg} / \mathrm{dl})$, these were administered via an antecubital vein and 18-gauge intravenous cannula at a rate of $4 \mathrm{cc} / \mathrm{sec}$ by means of an automatic injector (Medrad; Stellant CT injector). 
The scan delay was determined by using automated bolus-triggering software (Smart Prep; GE Healthcare, Milwaukee, Wis) program. Bolus tracking technique was used with a threshold of 120 $\mathrm{HU}$ in the descending aorta at the level of carina with.

CT angiography of the pulmonary and bronchial arteries with a combination of selected reformatted images was acquired.

Assessment of the lung parenchyma and airways as well as the mediastinum was done as in routine CT chest studies, using both lung parenchyma and mediastinal window settings.

\section{Post processing techniques:}

Post-processing of the raw data was performed by Transferred thin transverse CT images, Multiplanner Reformation (MPR), Maximum Intensity Projection (MIP), and Volume-Rendered (VR) technique, reviewed as digital images on a picture archiving and communication system workstation monitor (IMPAX, DS3000, AGFA).

Our aim was to evaluate the origins and courses of the bronchial arteries.

\section{Data interpretation:}

1- Evaluation of the lung parenchyma to localized the site of pathology and suspected bleeding, its cause as well as any associated findings.

2- Evaluation of the bronchial arteries considering the following:

A- The site of origin from the aorta.

\section{Results}

The study included 50 patients, complaining of hemoptysis.

CT chest with contrast was successful in identifying parenchymal cause of hemoptysis in 29/50 patients (58\%), 9 cases of them are showing pure parenchymatous abnormality with no vascular abnormality and the remaining 20 cases showed both parenchymatous and vascular abnormality.

Other cases with no parenchymatous abnormality, in which vascular cause is suspected was 21 cases, in these cases, MDCT angiography, revealed pure vascular origin in 15 cases. The remaining 6 cases showed no definite cause. Table (1).

The source of bleeding was classified according to the MDCT angiography into 20 cases with bronchial artery source, 8 cases with systemic non bronchial artery source, 7 cases with pulmonary source and 15 cases with non detected vascular source of bleeding. Table (2).

Conventional bronchial angiography was performed after MDCT study in 7 patients which require embolization.

In these cases with conventional angiography, dilated bronchial arteries were identified in 5 patients and dilated non bronchial systemic arteries were seen in 2 patients.

35 cases were detected with vascular abnormality, 15 case with pure vascular abnormality and the remaining 20 cases were associated with parenchymal abnormality.

These vascular abnormality were classified into 6 cases with bronchial artery aneurysm, 5 cases with pulmonary AVM, and 2 cases with pulmonary embolism.

The remaining cases (22 cases) showed only bronchial artery or systemic non bronchial artery dilatation.

MDCT angiography of the chest was successful in detecting 91 bronchial arteries in the 50 cases done. 35 out of the 91 bronchial arteries were right bronchial arteries and the remaining 56 were left bronchial arteries. On the other hand, 25 cases were with double left side bronchial arteries and 6 cases were with single left side bronchial arteries. Table (3).

Also, 20 artery of the 91 detected BAs were seen to be dilated $(>2 \mathrm{~mm}), 6$ of them with bronchial artery aneurysm and the other 14 arteries with just dilatation. 8 of the dilated bronchial arteries were right side and 12 were left side. Table (4).

Table (1): Classifications of the abnormalities detected in the cases of the study.

\begin{tabular}{lc}
\hline Abnormality detected & Number of cases \\
\hline Parenchymal only & 9 \\
Parenchymal and vascular & 20 \\
Pure vascular & 15 \\
None & 6 \\
\hline Total & 50 \\
\hline
\end{tabular}

Table (2): Different causes of bleeding in the cases.

\begin{tabular}{lc}
\hline Source of bleeding & Number of cases \\
\hline Bronchial artery & 20 \\
Systemic non bronchial artery & 8 \\
Pulmonary & 7 \\
No source detected & 15 \\
\hline
\end{tabular}


Table (3): Types and number of the detected bronchial arteries on each side in different cases of the study.

\begin{tabular}{|c|c|c|}
\hline & \multicolumn{2}{|c|}{ Bronchial arteries detected } \\
\hline & Right & Left \\
\hline Orthotopic & $22(62.9 \%)$ & $41(73.2 \%)$ \\
\hline Ectopic & $13(37.1 \%)$ & $15(26.8 \%)$ \\
\hline Total & 35 & 56 \\
\hline
\end{tabular}

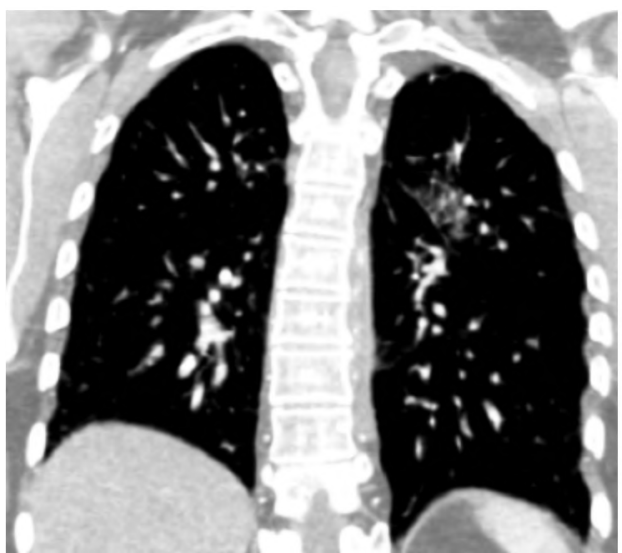

Fig. (1A): CT angiography showed:

- A small patch of ground glass opacity seen within the posterior segment of the left upper lung lobe ... Likely pulmonary haemorrhage in the view of the clinical data of haemoptysis.
Table (4): Number of dilated and non dilated bronchial arteries on each side in different cases of the study.

\begin{tabular}{|c|c|c|c|c|c|}
\hline & \multicolumn{4}{|c|}{ Bronchial arteries detected } & \multirow{3}{*}{ Total } \\
\hline & & Right & & Left & \\
\hline & Dilated & Non dilated & Dilated & Non dilated & \\
\hline Orthotopic & 5 & 17 & 6 & 35 & 63 \\
\hline Ectopic & 4 & 9 & 5 & 10 & 28 \\
\hline
\end{tabular}

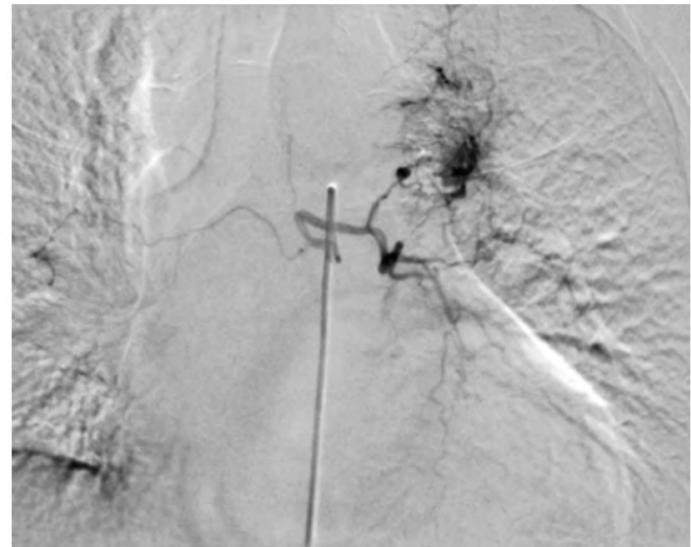

Fig. (1B): Bronchial angiography revealed:

- After reviewing the CT scan and determine the location of the left bronchial artery, Mickelsson catheter was then used to select the left bronchial artery. Contrast injection showed opacification of the left bronchial artery (small black arrow), along with right-sided branches (most likely inter-costals branches), along with parenchymal blush and suspicious area of micro-aneurysm (thick black arrow) supplying the area related to the bleeding site.

- The distal left bronchial artery was then embolized with PVA (355500 micros) till total stasis.

Fig. (1): 64 years old female patient with hyperparathyroidism presented with recurrent massive haemoptysis ( 400cc)

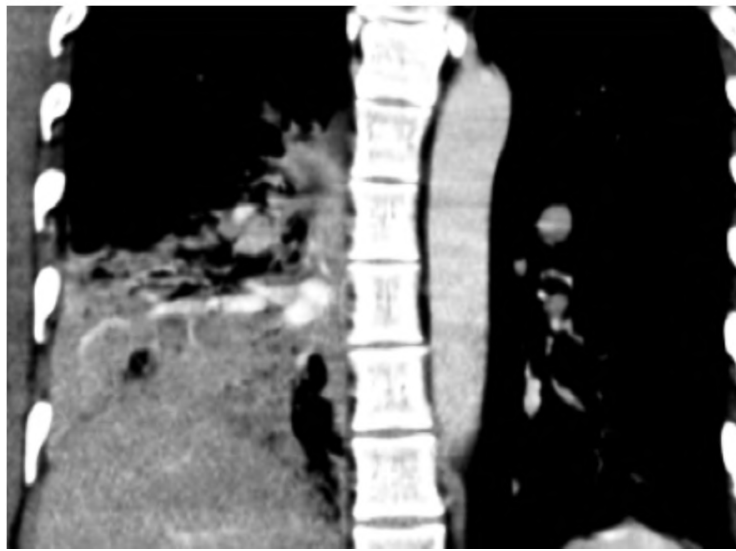

Fig. (2A): Pulmonary/aortic CT angiography phase after 6 seconds. Delayed phases after 19 and 45 seconds, revealed:

- No evidence of extra-vasation of the contrast media (no active bleeding).

- Abnormal mildly dilated right bronchial arteries are seen at D5-6 and D7-8 levels measuring upto $3 \mathrm{~mm}$ (thin black and white arrows).

- Abnormal density is seen inside the right lower lobe bronchus and the distal part of the bronchus intermedius ... In view of the patient clinical condition, suggestive of clotted blood (thick white arrow)

- There is increase in the size of the previously mentioned areas of pulmonary consolidation at the right middle and lower lung lobes.

- Mildly attenuated subsegmental pulmonary arteries at the right lower lung lobe.

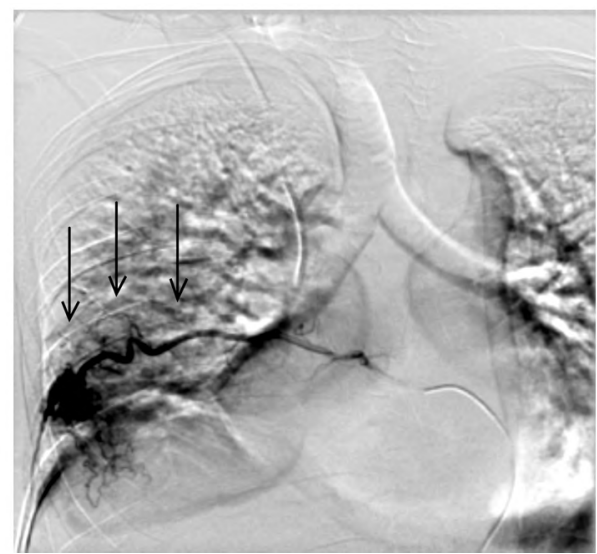

Fig. (2B): Bronchial angiography revealed:

- The main supply of the pathology located at the lower lobe of the right lung was identified as the right bronchial artery showing pathological branching and contrast stain (thin black arrows).

- Right bronchial artery was super selectively catheterised and embolotherapy was performed using polyvinyl alcohol particles of 300 to 500 micron sizes.

Fig. (2): 26 years old male patient presented with recurrent attacks of hemoptysis. 


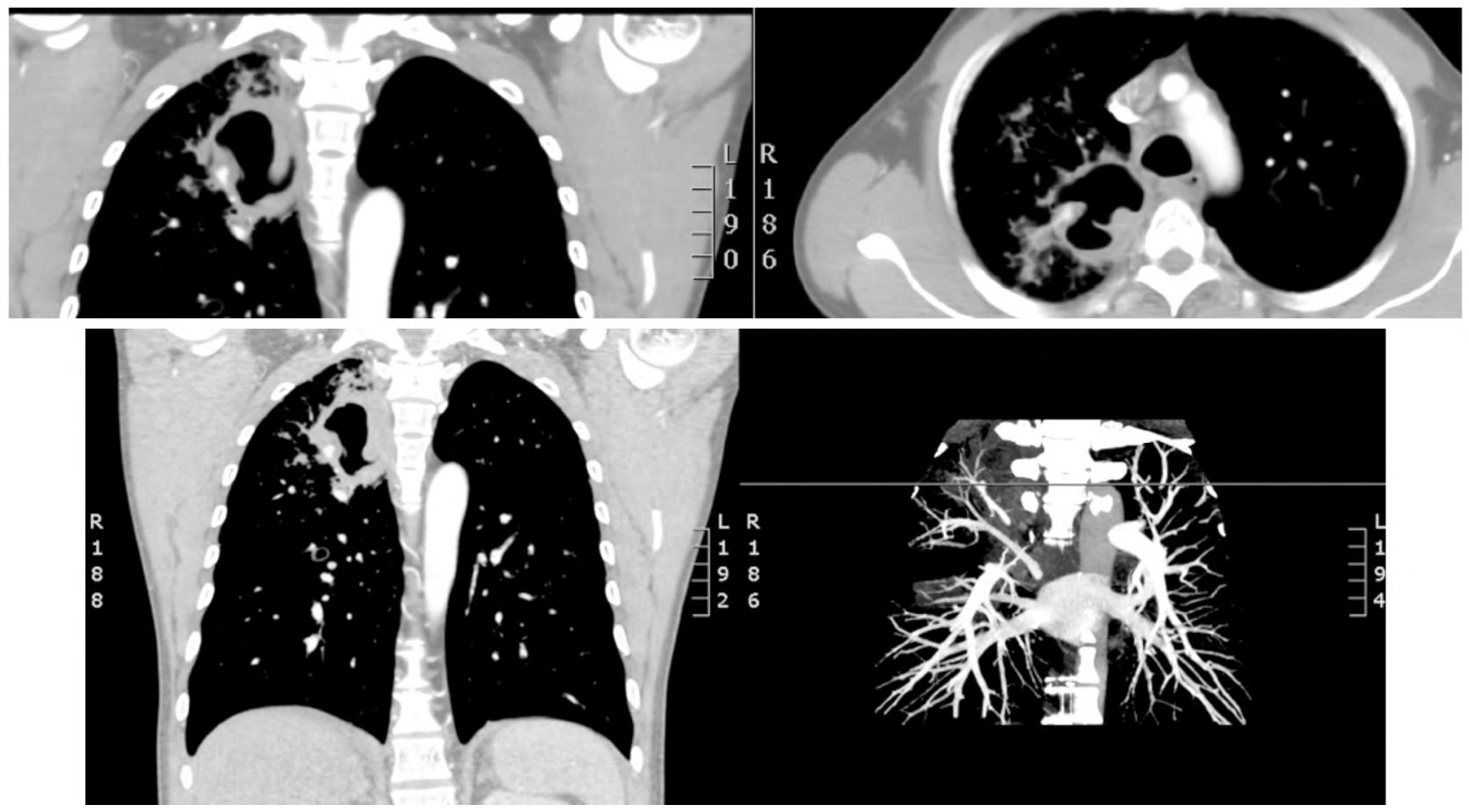

Fig. (3A): CT Thoracic Aorta Angiogram, Pulmonary Angiogram:

- A small focal area of aneurysmal dilatation of a branch of the right pulmonary artery arising from the upper lobe branch is noted. This is in close proximity to the wall of the cavity located in the posterior aspect of the right upper lobe which is suggestive of a mycotic aneurysm.

- No other abnormal feeding arteries are noted in the rest of the cavities.
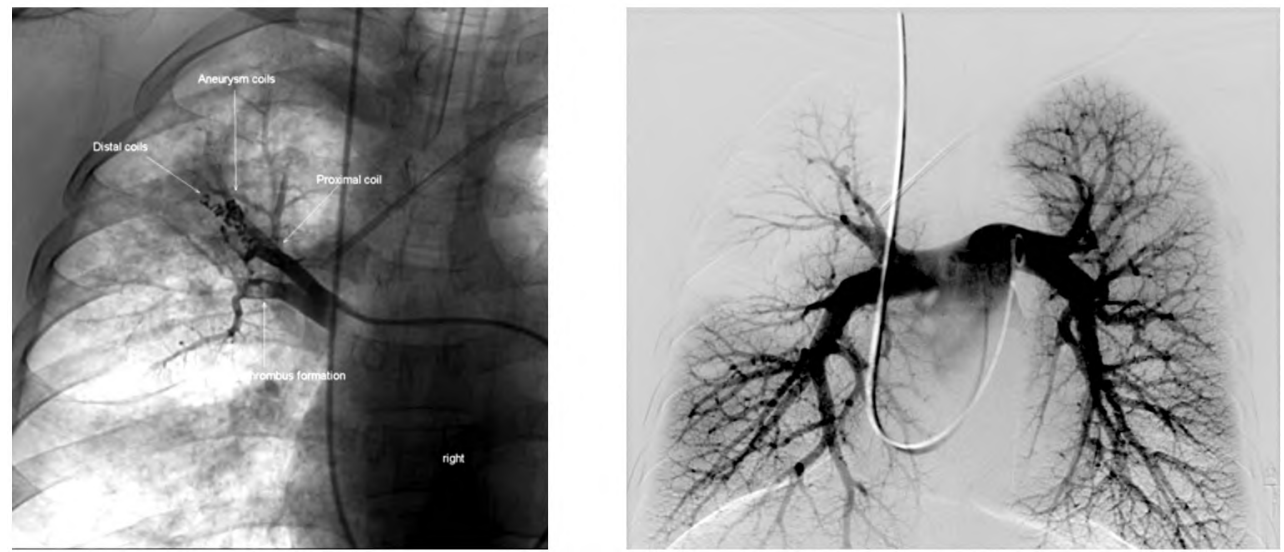

Fig. (3 B): Embolo-therapy of a branch of the right pulmonary artery, Pulmonary bronchial Angiogram revealed:

- The embolization of the right posterior upper segment pulmonary artery was done through the right internal jugular access by placing 11 pieces of $3 \mathrm{~mm} X 15 \mathrm{~mm}$ and 1 piece of $3 \mathrm{~mm}$ X $40 \mathrm{~mm}$ spring coils.

- The pre-embolization superselectiv angiography identified the supplier branch of the pulmonary artery along with the pseudo-aneurysm which were detected by the pulmonary angio-CT done same day.

- The post-embolization super-selective angiography confirmed complete occlusion of the false aneurysm as well as the supplying artery.

Fig. (3): 40 years old male patient presented at ICU (Intensive Care Unit) with Hemoptysis.

$30 \%$ of the detected bronchial arteries were ectopic (28/91 arteries) and the remaining 63 arteries were orthotopic. The ectopic arteries originated from the undersurface of the aortic arch (19 arteries), distal descending aorta (5 arteries), subclavian artery ( 3 arteries) and one from the brachi- ocephalic trunk. These 28 ectopic bronchial arteries were seen in 20 out of the 50 cases $(40 \%)$.

8 cases of non-bronchial systemic arteries as source of bleeding were detected. These vessels appear as abnormally dilated arteries that course into the lungs along trajectories that are not parallel 
to the bronchi (in contrast to the bronchial arteries). They are usually very tortuous and well depicted on reformatted images.

On axial images, their presence can often be predicted on the basis of pleural thickening greater than $3 \mathrm{~mm}$ with enhancing arteries within the extrapleural fat.

In 7 cases the pulmonary circulation was the source of bleeding with 5 cases due to pulmonary AVM or aneurysm and 2 cases due to pulmonary embolism.

\section{Discussion}

MDCT angiography was found to be so important in evaluating the cases of hemoptysis and classifying the causes and sources of bleeding. It also can be a guide for the radiologist and interventional radiologist about the next step in management.

In the cases which shows parenchymal abnormality, MDCT angiography helps in localizing the site of abnormality which can be further identified by bronchoscopy.

In the cases with vascular abnormality. MDCT angiography can indetify the source of bleeding either it is bronchial arteries either orthotpic or ectopic, non bronchial systemic arteries or pulmonary arteries. Bronchial arteries abnormalities includes aneurysm or just arterial dilatation. Non bronchial systemic arteries dilatation could also be identified. Pulmonary artery embolism or AVM were also other vascular cause of hemoptysis. Determining these vascular cause is of great value for planning the cases which needs interventional management.

In our study MDCT detected the cause of hemoptysis in 44 out of 50 cases (88\%) with no abnormality detected in 6 cases (12\%). This was near the results of Abdel-Ghany et al. [11], who found that MDCT detected the cause of hemoptysis in 42 of 50 patients (84\%). Also near the result of Khalil et al. [12], who detected the cause of bleeding by MDCT in 48 of 53 patients $(90.5 \%)$.

In our study, MDCT angiography detected 91 bronchial arteries in the 50 patient examined. In another study by Yoon et al. [13], they detected 52 bronchial arteries in 22 patients.

In our study 63 out of $91(69.2 \%)$ detected bronchial arteries were orthotopic while 28 (30.8\%) bronchial artery were ectopic. On the right side
$62.9 \%$ were orthotopic and $37.1 \%$ were ectopic. On the left side $73.2 \%$ were orthotopic and $26.8 \%$ were ectopic.

This is different from Abdel-Ghany et al. [11], who found $90 \%$ orthotopic bronchial arteries and only $10 \%$ ectopic in their study. Also Remy Jardin et al. [6], found the bronchial arteries to be orthotopic in $83 \%$ of cases and ectopic in $17 \%$ of cases on the right side. Also they found bronchial arteries to be orthotopic in $73 \%$ of cases and ectopic in $27 \%$ of cases on the left side.

Also Mori et al. [14], found 102 bronchial arteries in their study, among them $80(78.4 \%)$ were orthotopic and $22(21.6 \%)$ were ectopic.

In our study, $19(67.8 \%)$ of the detected ectopic arteries originated from the undersurface of the aortic arch, while 5 from the distal descending aorta, 3 from the subclavian artery, and the last one from the brachiocephalic trunk.

This was coinciding with Abdel-Ghany et al., [11], who detected 9 ectopic bronchial arteries, most of them from the aortic arch (7/9) and the remaining from the lower descending aorta and subclavian artery.

In our study the ectopic bronchial arteries were detected in $40 \%$ of patients. This nearly in agreement with Mori et al. [14], who detected ectopic bronchial vessels in $42 \%$ of patients, and also Hartmann et al. [15], who detected ectopic bronchial vessels in $36 \%$ of patients.

In our study 9 out of 35 (25.7\%) detected right bronchial arteries were dilated, while 11 out of 56 (19.6\%) detected left bronchial arteries were dilated. While in Mori et al., study [14], dilatation and tortuosity of BAs were found in 8 patients $(40 \%)$.

In our study 22 right orthotopic bronchial arteries detected, $13(59.1 \%)$ arised from the right intercostal bronchial trunk, 5 (22.7\%) arised from common trunk of both bronchial arteries, and 4 $(18.2 \%)$ arised directly from the thoracic aorta.

While 41 left orthotopic bronchial arteries were detected, $25(61 \%)$ arised directly from the thoracic aorta, $11(26.8 \%)$ arised from the left intercostal bronchial trunk, and $5(12.2 \%)$ arised from common trunk of both bronchial arteries.

While in the study performed by Morita et al. [16], 118 right bronchial arteries were detected, 61 $(52 \%)$ originated from the right intercostal bronchial trunk, $15(13 \%)$ originated directly from the thoracic aorta, $38(32 \%)$ originated from the com- 
mon trunk of both bronchial arteries, and four (3\%) originated from the right subclavian artery.

While in their study, 105 left bronchial arteries were detected. $63(60 \%)$ originated directly from the thoracic aorta, $38(36 \%)$ arose from the common trunk of both bronchial arteries and four (4\%) arose from the left intercostal bronchial trunk.

In our study, 8 cases of non-bronchial systemic arteries as source of bleeding were detected (16\%). These vessels appear as abnormally dilated arteries that course into the lungs along trajectories that are not parallel to the bronchi. They are usually very tortuous and well depicted on reformatted images. These arteries were originated from intercostal arteries.

Gupta et al., [17], had detected nonbronchial systemic arteries in 11 of 27 patients (40.7\%). Three of these patients (11.1\%) had normal bronchial arteries, and a nonbronchial systemic artery was the only source of hemoptysis. In another study by Yu-Tang Goh et al., [18], a 42 out of 103 patients who underwent bronchial artery embolization had nonbronchial systemic arteries associated with abnormal bronchial arteries (41\%), but also 12 had abnormal nonbronchial systemic arteries with normal bronchial arteries (11.7\%).

Also in study by Mohamed et al., [19], they identified non bronchial systemic arteries in 6 patients $(11.5 \%)$. They were in the form of dilated intercostals vessels with pleural thickening and in association with parenchymal lung abnormalities in all of these 6 patients.

In our study conventional angiography was done for 7 patients (14\%) indicated for embolization by MDCT. In 5 cases dilated bronchial arteries was detected, while in 2 cases dilated systemic non bronchial arteries are seen. In these cases embolization was done. It is important to identify these abnormal nonbronchial systemic arteries before embolization to achieve successful embolization and avoid recurrence hemoptysis. In the study performed by Abdel-Ghany et al., [11], conventional angiography was performed for 4 cases for embolization.

In our study, the pulmonary circulation was the source of bleeding in 7 patients (14\%). 5 cases with pulmonary AVM and 2 cases with pulmonary embolism. This was in agreement with the study performed by Mohamed et al., [19], in which the pulmonary circulation contributed to hemoptysis in 7 cases $(13.5 \%), 4$ of them had pulmonary embolism and 1 patient had AVM. In one patient, a branch from the Rt pulmonary artery was seen within the wall of a cavitary lesion in the right middle lobe.

In other previous studies, the pulmonary circulation contributed to hemoptysis in $6.9 \%$ of cases in Khalil et al., [20] and 10\% of cases in Abd ElGhany et al., [11].

\section{Conclusion:}

MDCT pulmonary and bronchial angiography is a very valuable technique in determining and the source and causes of hemoptysis and planning of management.

\section{References}

1- FRASER R.S., PARE P. and PARE P.D.: Hemoptysis. In: Fraser R.S., Pare P., Pare P.D., eds. Diseases of the chest. Philadelphia, Pa: Saunders, 394-6, 1988.

2- JEUDY J., KHAN A.R., MOHAMMED T., et al.: Expert panel on thoracic imaging. ACR appropriateness criteria Hemoptysis, J. Thorac. Imaging, 25 (3): W67-W69, 2010.

3- SOARES PIRES F., TEIXEIRA N., COELHO F., et al.: Hemoptysis etiology, evaluation and treatment in a university Hospital, Rev. Port. Pneumol., 17: 7-14, 2011.

4- GUPTA M., SRIVASTAVA D.N., SEITH A., et al.: Clinical impact of multidetector row computed tomography before bronchial artery embolization in patients with hemoptysis: A prospective study, Can. Assoc. Radiol. J., 64: 61-73, 2013.

5- HIRSHBERG B., BIRAN I., GLAZER M., et al.: Hemoptysis: Etiology, evaluation, and outcome in a tertiary referral hospital. Chest, 112: 440-4, 1997.

6- REMY-JARDIN M., BOUAZIZ N., DUMONT P., et al.: Bronchial and non-bronchial systemic arteries at multi detector row CT angiography: Comparison with conventional angiography. Radiology, 233: 741-9, 2004.

7- SIRAJUDDIN A. and MOHAMMED T.L.: A 44-year-old man with hemoptysis: A review of pertinent imaging studies and radiographic interventions, Cleve Clin. J. Med., 75: 601-7, 2008.

8- KAUCZOR H.U., SCHWICKERT H.C., MAYER E., et al.: Spiral CT of bronchial arteries in chronic thromboembolism. J. Comput. Assist. Tomogr., 18: 855-61, 1994.

9- LOPEZ J.K. and LEE H.Y.: Bronchial Artery Embolization for Treatment of Life-Threatening Hemoptysis. Semin Intervent Radiol., 23 (3): 223-9, 2006.

10- BRUZZI J.F., JARDIN M.R., DELHAYE D., et al.: MultiDetector Row CT of Hemoptysis. Radiographics, 26: 322, 2006.

11- ABD EL-GHANY A.F., NASSEF M.A. and OSMAN N.M.: Multidetector CT chest with bronchial and pulmonary angiography determining causes, site and vascular origin of bleeding inpatients with hemoptysis, Egypt. J. Radiol. Nucl. Med., 44: 769-78, 2013.

12- KHALIL A., PARROT A., NEDELCU C., et al.: Severe hemoptysis of pulmonary arterial origin: Signs and role 
of multi detector row CT angiography. Chest, 133: 2129, 2008.

13- YOON W., KIM Y.H., KIM J.K., et al.: Massive hemoptysis: Prediction of non bronchial systemic arterial supply with chest CT. Radiology, 227: 232-8, 2003.

14-MORI H., OHNO Y., TSUGE Y., et al.: Use of multidetector row $\mathrm{CT}$ to evaluate the need for bronchial arterial embolization in hemoptysis patients. Respiration, 80: 24-31, 2010.

15- HARTMANN I.J., REMY-JARDIN M., MENCHINI L., et al.: Ectopic origin of bronchial arteries: Assessment with multidetector helical CT angiography. Eur. Radiol., 17: 1943-53, 2007.

16- MORITA Y., TAKASE K., ICHIKAWA H., et al.: Bronchial artery anatomy: Preoperative 3D simulation with multidetector CT. Radiology, 255 (3): 934-43, 2010.
17- GUPTA M., SRIVASTAVA D.N., SEITH A., et al.: Clinical impact of multi detector row computed tomography before bronchial artery embolization in patients with hemoptysis: A prospective study, Can. Assoc. Radiol. J., 64: 61-73, 2013.

18- YU-TANG GOH P., LIN M., TEO N., et al.: Embolization for hemoptysis: A 6-year review. Cardiovasc Intervent Radiol., 25: 17-25, 2002.

19- MOHAMED S.A.A., MOUSA E.M., HAMED A.M., et al.: Abdel Aziz. Utility of multidetector row computed tomography in the management of hemoptysis: An experience from Upper Egypt. Egyptian Journal of Chest Diseases and Tuberculosis, 66 (4):723-8, 2017.

20- KHALIL A., FARTOUKH M., PARROT A., et al.: Impact of MDCT angiography on the management of patients with hemoptysis. AJR, 195: 772-8, 2010.

\title{
دور الآشعة الهقطعية الوعائية فى تقييه الآسباب الوعائية الدموية لنفث الدماثم
}

\author{
الهدف: يتمثل فى تقييم دود الآثعة المقطعية الوعائية في إكتثاف وتحديد مواقع نفث الدم فى حالات الآسباب الوعائية الدموية. \\ مرضى وطرق: دراسة مستَبلية ثملت • م مريضاً يعانون من نفث الدم، حيث تم عمل آثعة مقطعية بالصبغة المؤقتة الوعائية والفحص

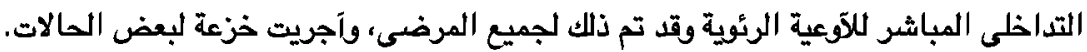

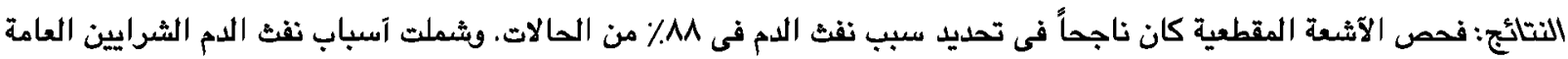 \\ وشرايين الشعب الهوائية. \\ الإستتاج: تصوير الآوعية الرئوية بالآثعة المقطعية الوعائية للآوعية العامة وآوعية الشعب الهوائية تمثل تقنية قيمة للغاية فى تصديد المصدر \\ والآسباب لنفث اللم والتخطيط للعلاج.
}

